\title{
Dielectric Resonator Antenna Mounted on Cylindrical Ground Plane for Handheld RFID Reader at 5.8 GHz
}

\author{
S. H. Zainud-Deen ${ }^{1}$, H. A. Malhat ${ }^{2}$, N. A. El-Shalaby ${ }^{3}$, and K. H. Awadalla ${ }^{4}$ \\ ${ }^{124}$ Faculty of Electronic Engineering, Menoufia University, Egypt. \\ ${ }^{3}$ Faculty of Engineering, Kafer Elshekh University, Egypt. \\ E.mail: ${ }^{1}$ anssaber@yahoo.com, ${ }^{3}$ noha1511ahm@yahoo.com, ${ }^{4}$ kamal_awadalla@hotmail.com \\ *corresponding author, E-mail: er_honida1@yahoo.com,
}

\begin{abstract}
Dielectric resonator antenna (DRA) mounted on cylindrical ground plane is investigated for handheld RFID reader applications at $5.8 \mathrm{GHz}$. The simplicity of the structure makes it practical in terms of cost, space, and ease of fabrication. The radiation characteristics of the antenna in free space and in the presence of a proposed compact reader device model and human hand are calculated. The antenna is circularly polarized and exhibits peak gain of $7.62 \mathrm{~dB}$ at $5.8 \mathrm{GHz}$ with high front to back ratio of $15.5 \mathrm{~dB}$. Using the same reader device model, a sequentially feeding $2 \times 2$ DRA array mounted on the same cylindrical ground plane is used for RFID reader antenna at $5.8 \mathrm{GHz}$. The array introduces high gain of $9.36 \mathrm{~dB}$ at $5.8 \mathrm{GHz}$ with high front to back ratio of $10.48 \mathrm{~dB}$. The $2 \times 2 \mathrm{DRA}$ array elements exhibit circular polarization over a frequency band of $1.1 \mathrm{GHz}$. The axial ratio is $1.1 \mathrm{~dB}$ at $5.8 \mathrm{GHz}$. The proposed reader model is simple and has a small size compared with that in the case of planar ground plane. The results are calculated using the finite element method (FEM) and compared with that calculated using the finite integral technique (FIT).
\end{abstract}

\section{Introduction}

Radio Frequency Identification (RFID) is a wireless technology which uses radio waves to automatically identify people or objects [1-3]. RFID has many advantages over the conventional automatic identification systems like long readable range, multiple access, high data rate, easy $\mathrm{read} / \mathrm{write}$ functions, and so on. An RFID system consists of a reader, a tag and a computer system. The reader is used to transmit radio frequency (RF) waves. These waves are received by the passive tag's antenna and used to power up the internal circuitry of the passive tag. The passive tag will modulate the waves generated by the reader in order to transmit its data back to the reader. The reader receives the modulated waves and converts them into digital data to be identified. The computer system is used for data handling and processing data. RFID systems typically use one of the frequency ranges: $125 \mathrm{KHz}, 13.56 \mathrm{MHz}, 868 \mathrm{MHz}, 928$ $\mathrm{MHz}, 2.45 \mathrm{GHz}$ and $5.8 \mathrm{GHz}$. RFID applications at microwave frequencies of $5.8 \mathrm{GHz}$ are tracking/ identification of goods, containers and packages, electronic seals, toll systems, fleet management, and pharmaceutical applications [1].
The RFID readers can be classified according to their application into two types, fixed reader type and handheld reader type. The reader antenna is an important component in the RFID system. Antennas for fixed RFID readers can be relatively large with high gain and low side lobe level such as antenna arrays [4]. Array antennas exhibit a narrower beamwidth and can implement beam scanning or switching-beam capabilities, so allowing for reading-rate rising, collision mitigation, item location finding in large and crowded environments $[5,6]$. Antennas for handheld readers must be compact low profile, small size, lightweight, high gain, and high front-to-back ratio such as helical antenna, microstip antenna and printed antennas [7-9]. The RFID reader antenna has been designed with circularly polarized (CP) operation. $\mathrm{CP}$ for the reader antennas in transmission is preferred because the tag antenna (which is linearly polarized) will receive enough power from the transmitter irrespective of its orientation. Handheld antennas are likely to be close to the human body. Therefore, for the associated health issue, the high front-to-back ratio can prevent users from exposure to any intense back radiation in a handheld application [7].

Dielectric resonator antennas (DRAs) have been widely used in many applications especially in satellite communications, mobile communications and RFID systems. Advantages of these antennas include small size, light weight, low profile, high gain, high radiation efficiency due to the absence of conduction or surface wave losses, ease of excitation and wide bandwidth [10-12]. Various shapes of DRAs are available, these include cylindrical, half-cylindrical, hemispherical, rectangular, triangular, etc. A circularly polarized cylindrical dielectric resonator antenna for portable RFID reader using a single feed has been investigated in [13]. The radiation characteristics of the antenna in the presence of a reader device and a human hand model have been introduced. In previous studies, the radiation characteristics of the DRA mounted on a planar ground plane structures have been investigated in [10]. The radiation characteristics of the DRA mounted on or embedded in curved ground plane structures with different shapes have been investigated in [14-16]. Sometimes placing the DRA over a curved ground plane helps to reduce the total size of the reader device than that of a planar ground plane case. 
In this paper, a DRA mounted on cylindrical ground plane is investigated for handheld RFID reader applications at 5.8 $\mathrm{GHz}$. The finite element method (FEM) is used to design and analyze the radiation characteristics of the proposed DRA antenna [17]. The results calculated using the FEM are compared with that calculated using the finite integration technique (FIT) [18], which is basically different from the FEM technique. The sequentially feeding technique is applied in order to improve the antenna gain and circular polarization of the DRA.

\section{Numerical Results}

\subsection{Antenna configuration}

Figure.1 illustrates the top and side views of the DRA element. The DRA antenna has a square cross section with length $a$, and height $\mathrm{H}_{\mathrm{d}}=10.2 \mathrm{~mm}$, where $a / \mathrm{H}_{\mathrm{d}}=1.25$. The DRA material has a dielectric constant $\varepsilon_{\mathrm{r}}=9.4$. Two triangles are removed from two corners along one diagonal of the square DRA with side length, $\mathrm{C}=5.3 \mathrm{~mm}$. By cutting the two corners of the DRA, two orthogonal modes are generated to produce circular polarization [19]. A coaxial feeding probe located off the DRA center by a distance $d_{f}$ $=5.1 \mathrm{~mm}$, height $\mathrm{h}_{\mathrm{f}}$ of $5.1 \mathrm{~mm}$ and radius of $0.15 \mathrm{~mm}$ is used to excite the DRA element. The dimensions of the DRA element are designed to operate at the RFID frequency 5.8 GHz. The DRA element is mounted on a circular cylindrical ground plane with length $\mathrm{L}_{\mathrm{g}}=110 \mathrm{~mm}$, and radius of curvature $R_{g}=27.5 \mathrm{~mm}$ as shown in Fig. 1 .
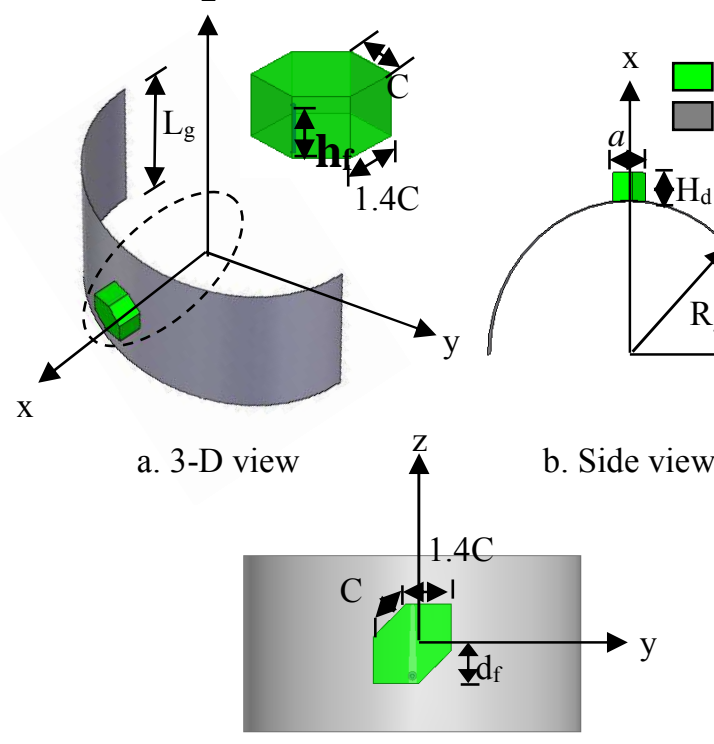

c. Top view

Fig.1. The geometry of circularly polarized DRA element mounted on a cylindrical ground plane. $\mathrm{Lg}_{\mathrm{g}}=110 \mathrm{~mm}$, $\mathrm{R}_{\mathrm{g}}=27.5 \mathrm{~mm}, \mathrm{H}_{\mathrm{d}}=11.9 \mathrm{~mm}$ and $\mathrm{C}=5.312 \mathrm{~mm}$.

The simulated reflection coefficient, $\mathrm{S}_{11}$, and the input impedance versus the operating frequency are shown in Fig.2. The results are calculated using the FEM and compared with those calculated by the FIT. The two sets of results agree well with each other. The antenna exhibits impedance matching bandwidth of $1.5 \mathrm{GHz}$ with $50 \Omega$ coaxial cable (from $5 \mathrm{GHz}$ to $6.5 \mathrm{GHz}$ for $\mathrm{S}_{11} \leq-10 \mathrm{~dB}$ ). The axial ratio, $\mathrm{AR}$, and antenna gain variations with frequency are illustrated in Fig.3. The antenna produces circular polarization with bandwidth $(\mathrm{AR}<3 \mathrm{~dB}) 2.6 \%(150 \mathrm{MHz})$ with respect to the center frequency at $5.8 \mathrm{GHz}$. The cone angle within which the AR is less than $3 \mathrm{~dB}$ is about $41^{\circ}$ in both the $\mathrm{x}-\mathrm{z}$ and $\mathrm{x}-\mathrm{y}$ planes at $5.8 \mathrm{GHz}$. The antenna gain varies from $4.88 \mathrm{~dB}$ to $5.18 \mathrm{~dB}$ over the RFID band from $5.65 \mathrm{GHz}$ to $5.95 \mathrm{GHz}$. Figure 4 shows the simulated circular polarization radiation patterns components left-hand $E_{L}$, and right-hand $E_{R}$, for the antenna at resonant frequency $5.8 \mathrm{GHz}$. The presence of the perfectly conducting cylindrical ground plane results in high front to back ratio of $14.5 \mathrm{~dB}$ in both the $\mathrm{x}-\mathrm{z}$ and $\mathrm{x}-\mathrm{y}$ planes. The ratio of $\mathrm{E}_{\mathrm{L}}$ to $\mathrm{E}_{\mathrm{R}}$ components is $17 \mathrm{~dB}$ at $\theta=90^{\circ}$ in $\mathrm{X}-\mathrm{z}$ plane.

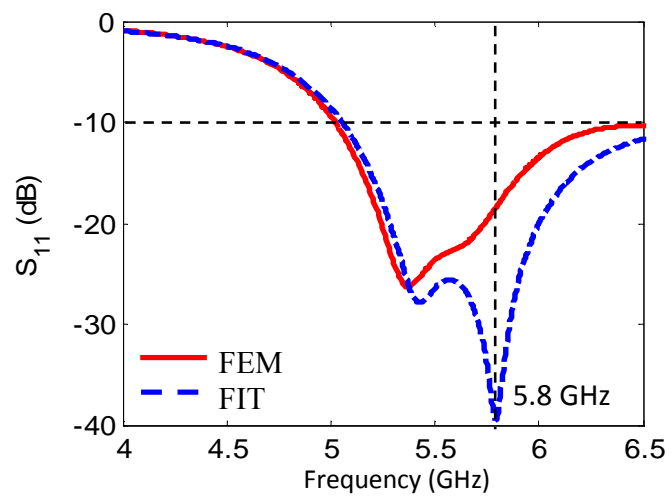

a. The reflection coefficient

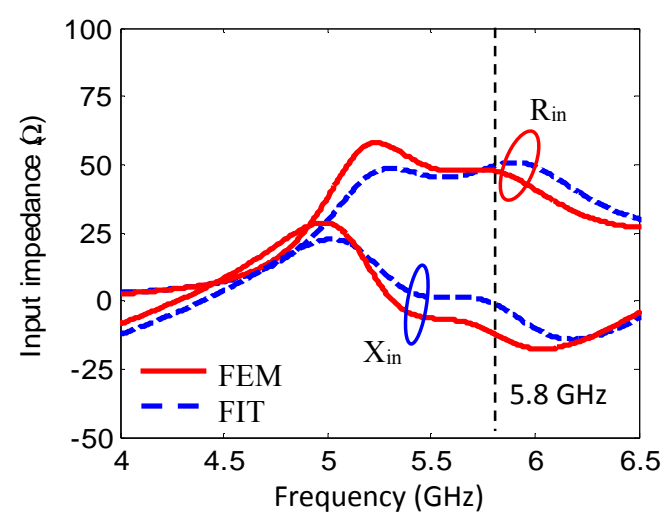

b. The input impedance

Fig.2. The reflection coefficient and the input impedance of the circularly polarized DRA element mounted on a cylindrical ground plane in free space.

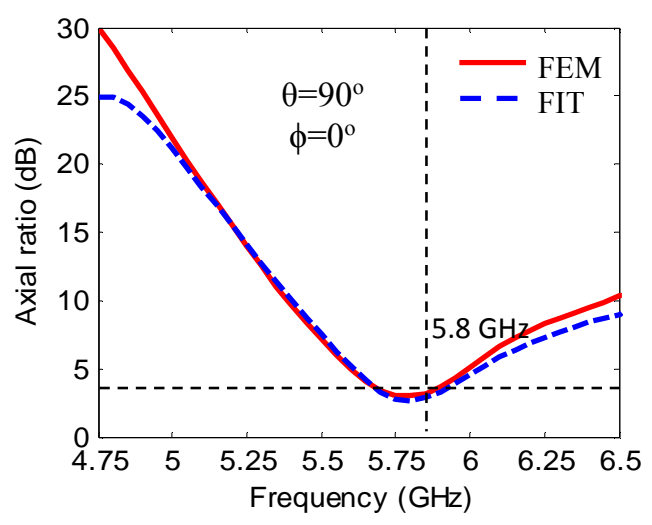




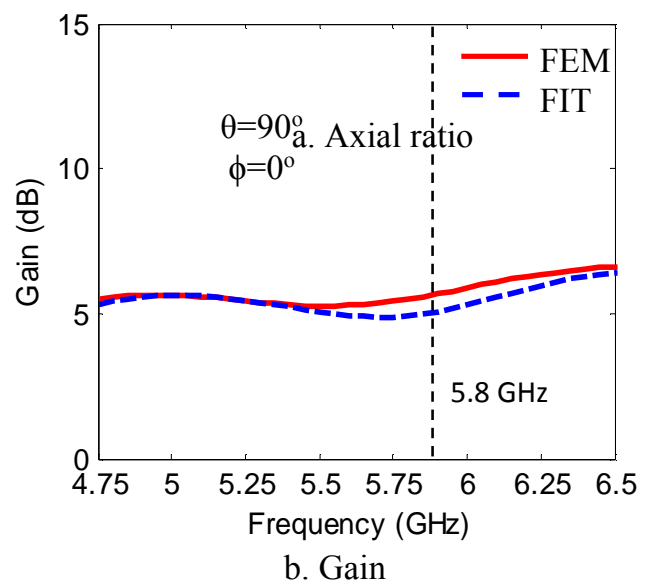

Fig.3. The axial ratio and gain of the circularly polarized DRA element mounted on a cylindrical ground plane in free space.

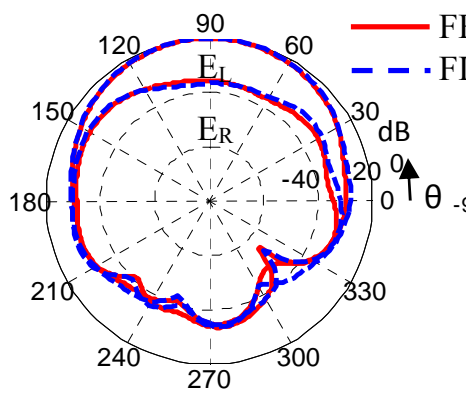

a. X-z plane

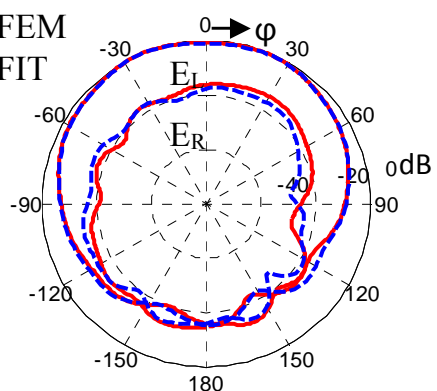

b. x-y plane
Fig.4. The circular polarization radiation pattern components of the circularly polarized DRA element mounted on a cylindrical ground plane in free space, at $\mathrm{f}=5.8 \mathrm{GHz}$.

In Fig.5. DRA antenna is placed inside a simulated model for the handheld RFID reader device in the presence of a human hand model. The detailed dimensions of the reader model and the human hand model [20] are presented in Table 1. The presented model is designed to obtain a main beam in the $\mathrm{x}$-axis direction. The proposed handheld reader device is more compact in thickness $(6.3 \mathrm{~cm})$ compared to the reader model presented in [21] with thickness of $(9.8$ $\mathrm{cm})$.

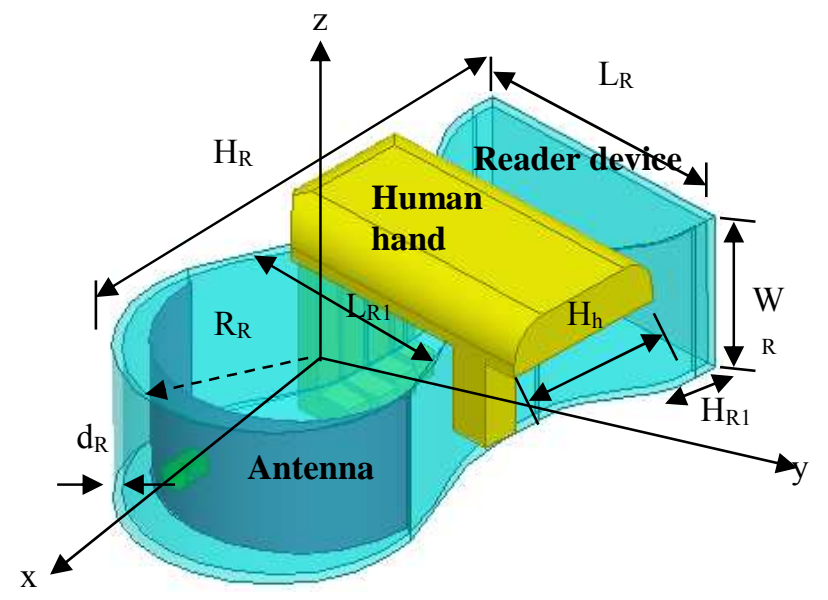

a. 3-D view

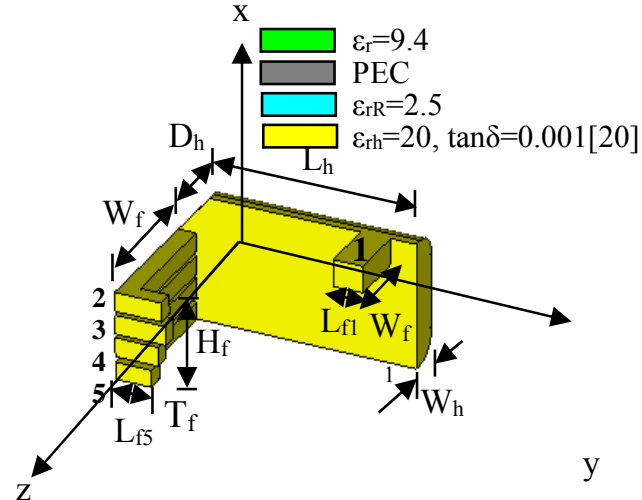

b. 3-D view of human hand model

Fig.5. The geometry of circularly polarized DRA element mounted on a cylindrical ground plane placed inside a reader device in the presence of human hand model.

\begin{tabular}{|c|c|c|c|c|c|}
\hline $\mathrm{H}_{\mathrm{R}}$ & 231 & $\mathrm{H}_{\mathrm{h}}$ & 72.6 & $\mathrm{~L}_{\mathrm{f} 2}$ & 26 \\
\hline $\mathrm{R}_{\mathrm{R}}$ & 53.6 & $\mathrm{~L}_{\mathrm{h}}$ & 114 & $\mathrm{~L}_{\mathrm{f} 3}$ & 28 \\
\hline $\mathrm{L}_{\mathrm{R}}$ & 114 & $\mathrm{H}_{\mathrm{f}}$ & 50.6 & $\mathrm{~L}_{\mathrm{f} 4}$ & 24 \\
\hline $\mathrm{W}_{\mathrm{R}}$ & 63 & $\mathrm{~W}_{\mathrm{h}}$ & 20 & $\mathrm{~L}_{\mathrm{f} 5}$ & 20 \\
\hline $\mathrm{L}_{\mathrm{R} 1}$ & 70 & $D_{h}$ & 28.3 & $\mathrm{~T}_{\mathrm{f}}$ & 10 \\
\hline $\mathrm{d}_{\mathrm{R}}$ & 2 & $\mathrm{~L}_{\mathrm{f} 1}$ & 16.5 & $\mathrm{~W}_{\mathrm{f} 1}$ & 35 \\
\hline $\mathrm{H}_{\mathrm{R} 1}$ & 20 & & & & \\
\hline
\end{tabular}

The reader is designed to reduce the electromagnetic radiation in the back direction towards the human operator and reduces the effect of the reader device and human operator on the radiation characteristics of the antenna. The hand position will be always in the direction of the back radiation from the antenna at a distance behind the ground plane. Figure 6 shows the simulated reflection coefficient of the structure and the input impedance against the frequency. The impedance matching range for the reflection coefficient is less than $-10 \mathrm{~dB}$ from $5 \mathrm{GHz}$ up to $6.5 \mathrm{GHz}$ resulting in frequency bandwidth more than $1.5 \mathrm{GHz}(25.86 \%)$. The circular polarization characteristics of the antenna in the presence of the reader device and human hand model are investigated.

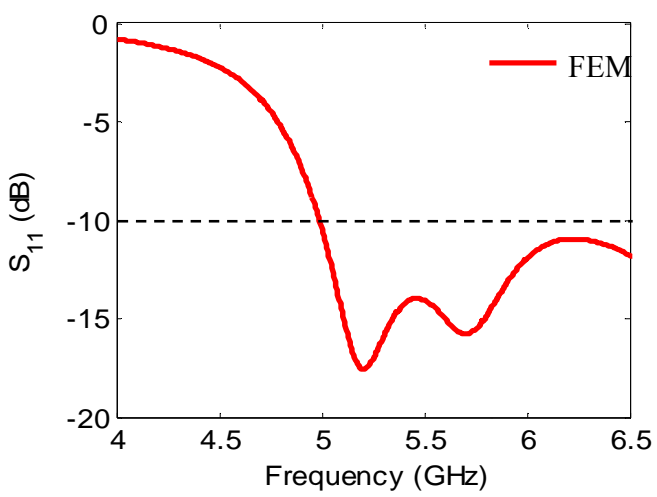

a. The reflection coefficient 


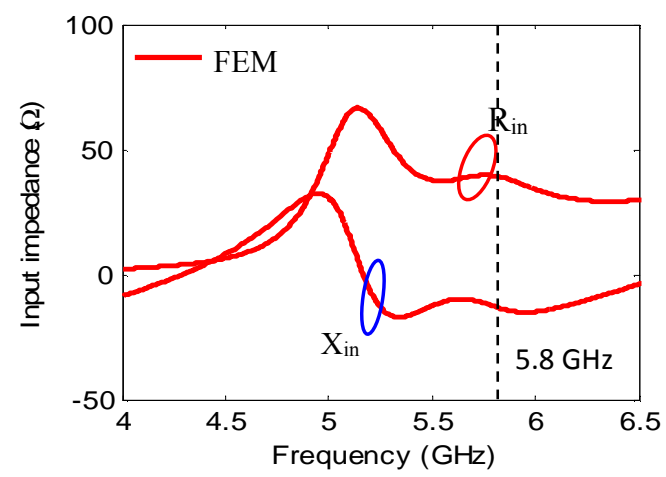

b. The input impedance

Fig.6. The reflection coefficient and the input impedance of the circularly polarized DRA element mounted on a cylindrical ground plane in the presence of the reader device and human hand model.

Figure 7 exhibits the simulated $\mathrm{AR}$ in the direction of the main beam versus frequency. The $3-\mathrm{dB}$ AR bandwidth is $170 \mathrm{MHz}$ or $3 \%$ (from $5.68 \mathrm{GHz}$ to $5.85 \mathrm{GHz}$ ) relative to the resonance frequency. The antenna has gain of $7.62 \mathrm{~dB}$ at $5.8 \mathrm{GHz}$ (compared with $5 \mathrm{~dB}$ in free space). The gain is increased due to the dielectric body of the reader device which works as a superstrate layer mounted on the DRA antenna. The far-field radiation patterns of both $E_{L}$ and $E_{R}$ field component $\mathrm{s}$ for the designed antenna at resonant frequency $5.8 \mathrm{GHz}$ are shown in Fig.8. The front to back ratio is $15.5 \mathrm{~dB}$. The presences of the reader device and human hand model have nearly little effect on the radiation characteristics of the DRA antenna as they are located in the back direction of the antenna.

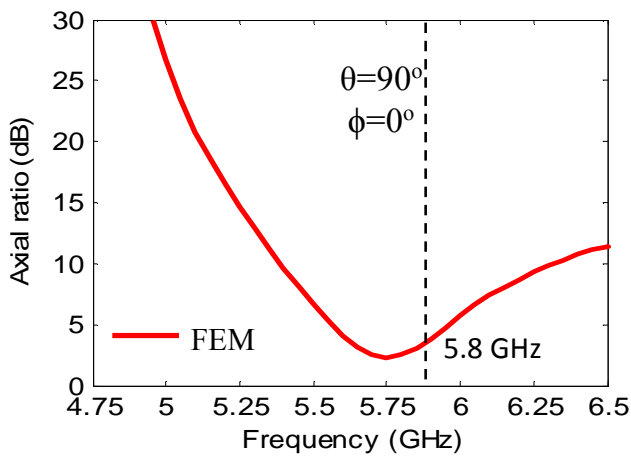

a. Axial ratio

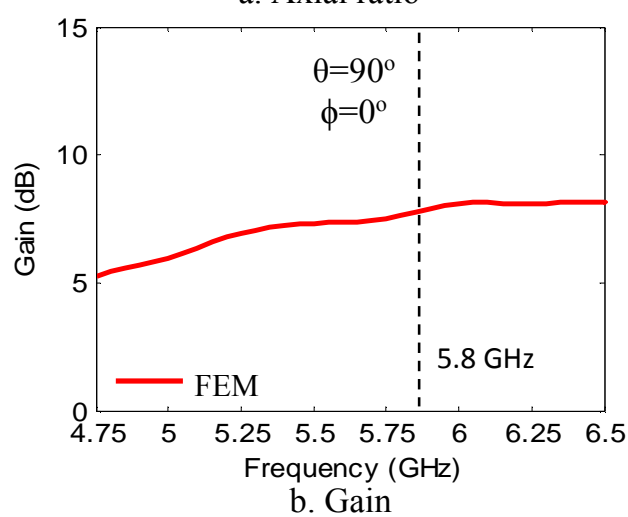

Fig.7. The gain and axial ratio of the circularly polarized DRA element mounted on a cylindrical ground plane placed inside a reader device and with the human hand model.

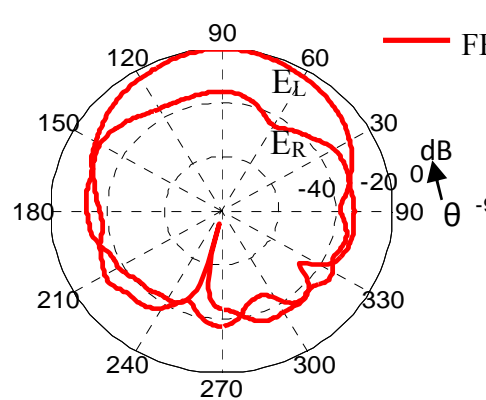

a. X-Z plane

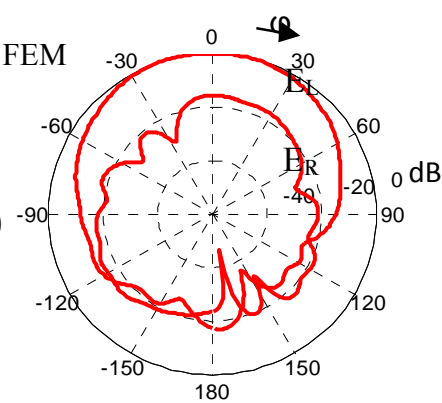

b. $x-y$ plane
Fig.8. The circular polarization radiation pattern components of the circularly polarized DRA element mounted on a cylindrical ground plane placed inside a reader device and with the human hand model, at $\mathrm{f}=5.8$ $\mathrm{GHz}$.

\section{2. $2 \times 2$ DRA Array}

Figure 9 shows $2 \times 2$ DRA array mounted on cylindrical ground plane structure in free space with, $\mathrm{L}_{\mathrm{g}}=55 \mathrm{~mm}$, and radius $\mathrm{R}_{\mathrm{g}}=55 \mathrm{~mm}$. The arc distance between the centres of the adjacent elements is $\lambda / 2$ in order to reduce the mutual coupling between them [19]. In order to increase the circular polarization bandwidth and gain of the DRA array elements the sequential feeding technique is applied [22].

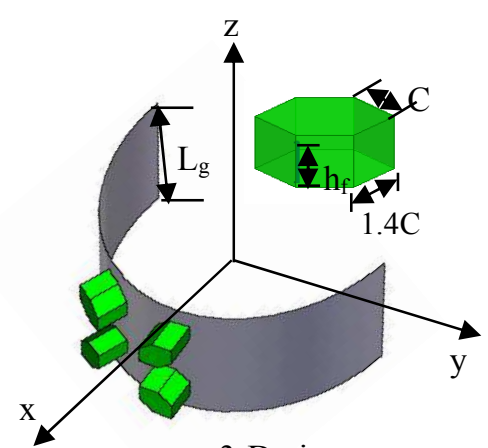

a. 3-D view

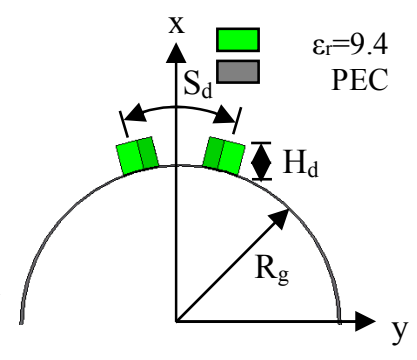

b. Side view

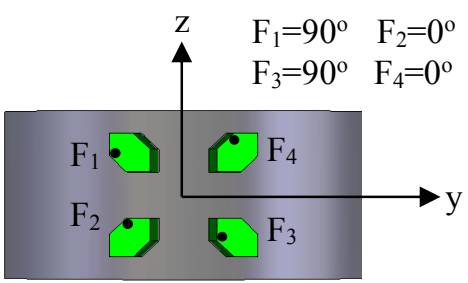

c. Top view

Fig.9. The geometry of the $2 \times 2$ circularly polarized DRA array elements mounted on a cylindrical ground plane in free space.

In the sequential feeding technique, each element is fed uniformly in power amplitude. The four element array proposed to enhance the circular polarization transmission can be considered as two sub-arrays with each sub-array consists of two dielectric resonators placed on the same diagonal of the square that they are positioned at its corners. The two elements of one of the sub-arrays is fed with $0^{\circ}$ phase and the elements of the other sub-array are fed with $90^{\circ}$ phase as shown in Fig. 10. The four elements are identical, but the two of the $0^{\circ}$ phased array are similarly 
oriented, and the other two elements of the second sub-array are rotated $90^{\circ}$ in space. If each element is represented by an infinitesimal dipole, the system becomes two perpendicular sub-arrays, with each sub-array is producing a field perpendicular in space to the field produced by the second and different by $90^{\circ}$ in phase. As all the elements are fed with signal $\mathrm{s}$ of equal magnitude, the two sub-arrays produce equal magnitude fields at the same point in the broadside direction (x-direction), but are perpendicular in space and having $90^{\circ}$ difference in phase. Thus, a circularly polarized resultant field is radiated in the broadside direction. This resultant field is having an axial symmetry around the $\mathrm{x}$-axis because of the physical symmetry of the four elements around the x-axis, and also having a wide bandwidth because of the wideband of the dielectric resonator elements.

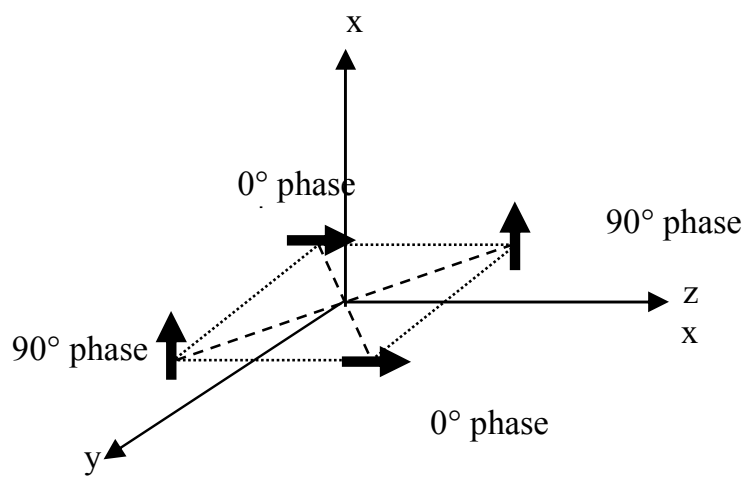

Fig. 10. The equivalent four infinitesimal dipole element array.

The computed frequency response of the reflection coefficient and the input impeda nce at each port are shown in Fig.11. The antenna array has good impedance matching covering most of the operating frequency band up from 5 GHz. The frequency response of the axial ratio and the antera gain are illustrated in Fig. 12. It is clearly seen that the Gandwidth, determined for $3 \mathrm{~dB}$ axial ratio, is $21.6 \%$ (1.2 $\mathrm{EHz}$ ). The cone angle within which the AR is less than $3 \mathrm{~dB}$ is about $103^{\circ}$ and $53^{\circ}$ in the $\mathrm{x}-\mathrm{z}$ and $\mathrm{x}-\mathrm{y}$ planes at 5.8 GHzrespectively. The antenna gain ranges from $6 \mathrm{~dB}$ at 4.5 GHzôo $10.5 \mathrm{~dB}$ at $6.5 \mathrm{GHz}$, and from 10.63 to $10.8 \mathrm{~dB}$ over the fole RFID band.

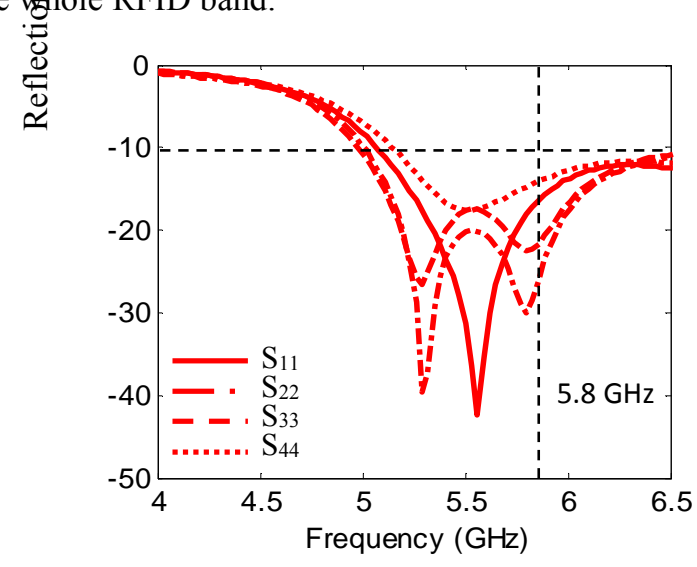

a. The reflection coefficient

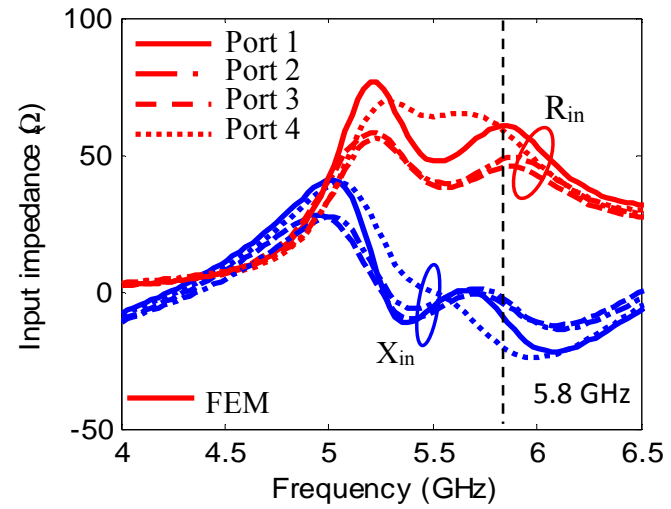

b. The input impedance

Fig.11. The reflection coefficient and the input impedance of the $2 \times 2$ circularly polarized DRA array elements mounted on a cylindrical ground plane in free space.

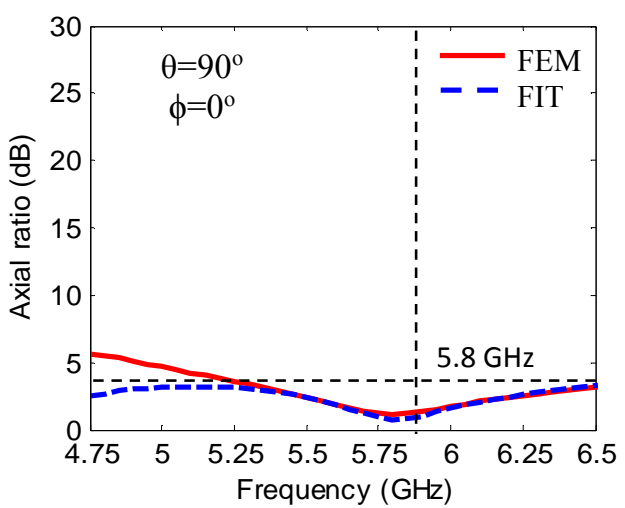

a. Axial ratio

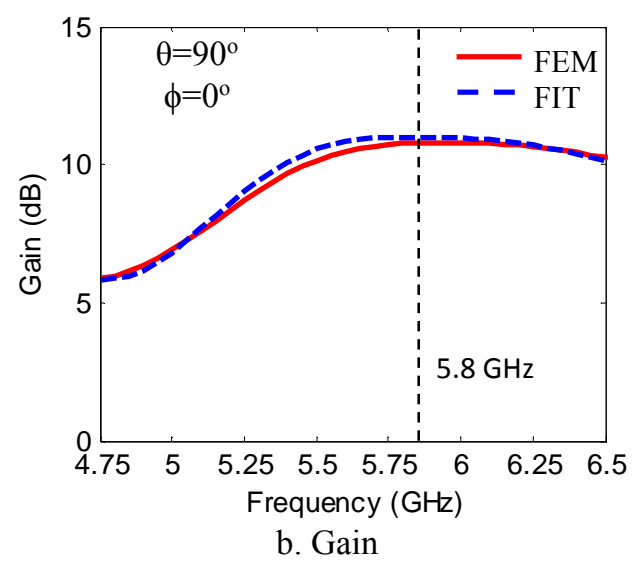

Fig.12. The axial ratio and gain of the $2 \times 2$ circularly polarized DRA array elements mounted on a cylindrical ground plane in free space.

The simulated far-field radiation patterns of both $E_{L}$ and $E_{R}$ for the designed antenna at resonant frequency $5.8 \mathrm{GHz}$ is shown in Fig.13. The presence of the perfectly conducting ground plane results in high front to back ratio of $17.28 \mathrm{~dB}$ in both the $x-y$ and $x-z$ planes, also, the $E_{L}$ to $E_{R}$ ratio is $15.7 \mathrm{~dB}$ at the resonance frequency. This indicates that the array structure has enhanced the performance in all aspects. 
Also, the size of the dielectric elements is reasonably small and consequently the size of the array is suitable for installments on the RFID reader.

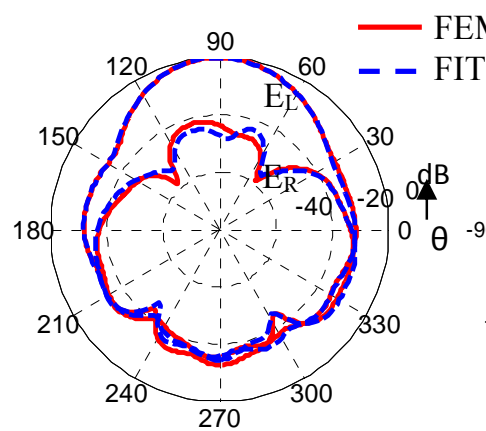

a. $\mathrm{x}-\mathrm{z}$ plane

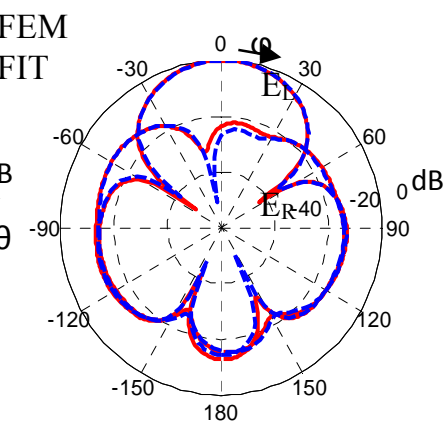

b. $x-y$ plane
Fig.13. The circular polarization radiation pattern components of the $2 \times 2$ circularly polarized DRA array elements mounted on a cylindrical ground plane in free space, at $\mathrm{f}=5.8 \mathrm{GHz}$.

The proposed $2 \times 2$ DRA array elements are placed in the same handheld reader device in the presence of human hand model as shown in Fig.14.a. The detailed dimensions are presented as in Table 1 . The proposed handheld reader device has the same dimensions $\left(23.1 \times 11.4 \times 6.3 \mathrm{~cm}^{3}\right)$. of that used with a single DRA element presented in section 2.2, while the reader model presented in [21] require to double the size of the reader in order to fit the DRA elements $\left(15 \times 16 \times 19.6 \mathrm{~cm}^{3}\right)$. The presented model is designed to obtain the main beam in the $\mathrm{x}$-axis direction. Fig.14.b. shows the simulated reflection coefficient of the $2 \times 2$ DRA elements mounted on the reader device in the presence of a human hand model. The impedance matching bandwidth range for return loss less than $-10 \mathrm{~dB}$ is $5 \mathrm{GHz}$ up to $6.5 \mathrm{GHz}$ resulting in frequency bandwidth more than 1.5 $\mathrm{GHz}(26 \%)$. Figure 15 shows the simulated AR in the direction of the main beam versus frequency. 3-dB AR bandwidth of $5.4 \mathrm{GHz}$ up to $6.5 \mathrm{GHz}$ or $19 \%$ relative to the resonance frequency is obtained. The simulated boresight gain is illustrated in the same figure. The gain is $9.36 \mathrm{~dB}$ at $5.8 \mathrm{GHz}$.

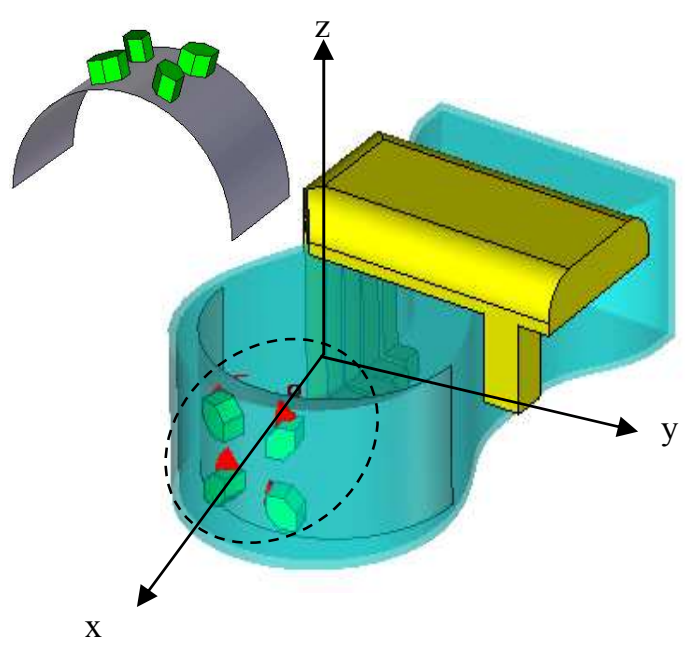

a. 3-D view

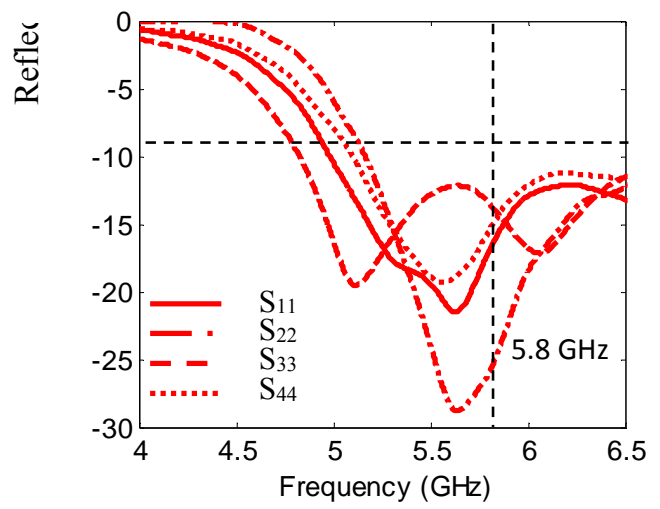

b. The reflection coefficient

Fig.14. The 3-D view and reflection coefficient of $2 \times 2$ circularly polarized DRA array elements mounted on a cylindrical ground plane placed inside a reader device in the presence of human hand model with the same dimensions as in Table 1.

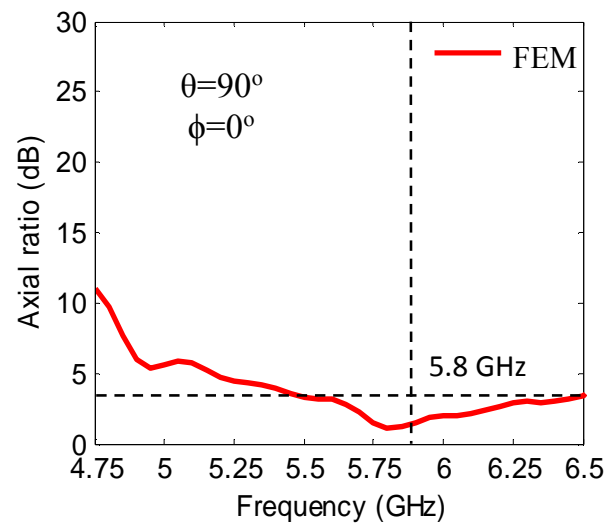

a. Axial ratio

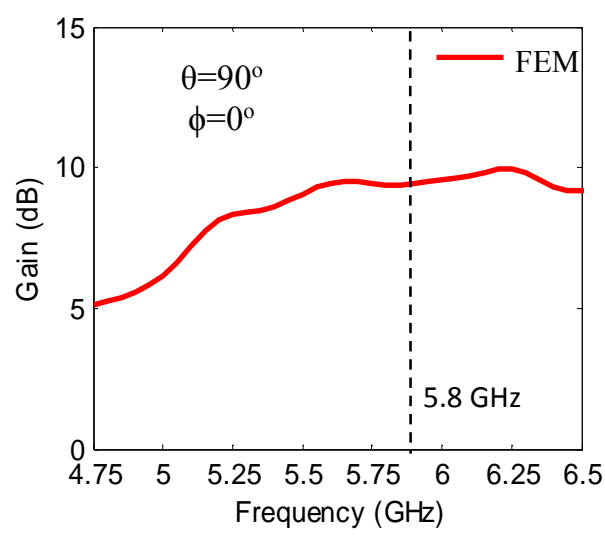

b. Gain

Fig. 15 . The axial ratio and gain of the $2 \times 2$ circularly polarized DRA array elements mounted on a cylindrical ground plane placed inside a reader device in the presence of human hand model with the same dimensions as in Table 1. 
Figure 16 shows the far-field radiation patterns of both copolarized $\mathrm{E}_{\mathrm{L}}$ and cross-polarized $\mathrm{E}_{\mathrm{R}}$ field components for the designed antenna at resonant frequency of $5.8 \mathrm{GHz}$. The front to back ratio is $10.48 \mathrm{~dB}$. Thus the presences of the reader device and human hand model have little effect on the radiation characteristics of the DRA. Thus with the proposed reader device and antenna arrangement, the size and other simulated human hand model parameters have no effect on the antenna performance. The $E_{L}$ to $E_{R}$ ratio is 23.8 $\mathrm{dB}$ at the resonance frequency. Thus in the previous models the impedance bandwidths, gain, AR bandwidth, front to back ratio and $E_{L}$ to $E_{R}$ ratio are quite suitable for the RFID reader applications.

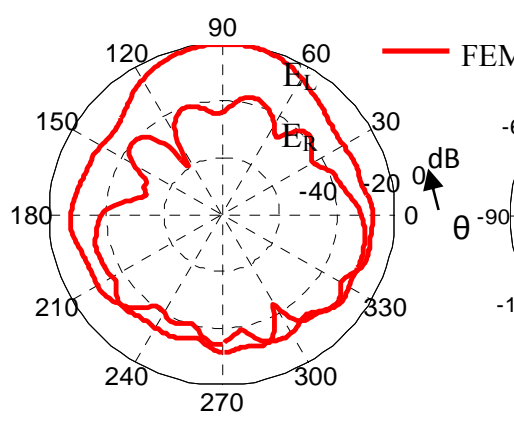

a. X-z plane

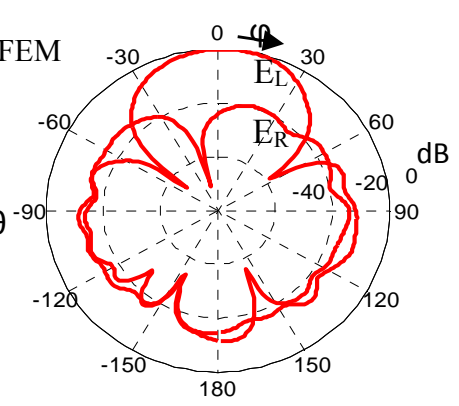

b. x-y plane
Fig.16. The circular polarization radiation pattern components of the $2 \times 2$ circularly polarized DRA array elements mounted on a cylindrical ground plane placed inside a reader device in the presence of human hand model with the same dimensions as in Table 1 , at $\mathrm{f}=5.8 \mathrm{GHz}$.

\section{Conclusions}

A circularly polarized dielectric resonator antenna mounted on a cylindrical metallic ground plane for handheld RFID reader at $5.8 \mathrm{GHz}$ is proposed. The radiation characteristics of the antenna are investigated. The results are calculated using FEM and compared with that calculated using FIT for verification. The antenna exhibits impedance matching bandwidth of $1.5 \mathrm{GHz}$ with $\mathrm{AR}<3 \mathrm{~dB}$ covering $150 \mathrm{MHz}$. The radiation characteristics of the antenna in the presence of a handheld reader device and human hand model are investigated. The proposed reader model is compact in size, and the antenna gain is increased to $7.62 \mathrm{~dB}$ at $5.8 \mathrm{GHz}$. The sequential feeding technique is applied to $2 \times 2$ DRA array elements in order to increase the antenna gain and circular polarization bandwidth. The radiation characteristics of the $2 \times 2$ DRA array are investigated in the presence of the reader device. The antenna gain is $9.36 \mathrm{~dB}$ with front to back ratio of $10.48 \mathrm{~dB}$ at $5.8 \mathrm{GHz}$. The presences of the reader device and human hand model have little effect on the radiation characteristics of the DRA antenna as they are located in the back direction of the antenna.

\section{References}

[1] K. Finkenzeller, RFID handbook: radio- frequency identification fundamentals and applications, $2^{\text {nd }} E d$., Wiley \& Sons, Inc., New Jersey, USA, 2004.

[2] B. Manish and M. Shahram, RFID field guide: deploying radio frequency identification systems, Prentice Hall PTR, 2005.

[3] H. Bhatt, and B. Glover, RFID essentials, O'Reilly Media, Inc., Sebastopol, California, USA. 2006.

[4] S.H. Zainud-Deen, S.M. Gaber, Hend A. Malhat, and K. H. Awadalla," Multilayer dielectric resonator antenna transmitarray for near-field and far-field fixed RFID reader," Progress In Electromagnetics Research C, PIER C, vol. 27, pp. 129-142, 2012.

[5] Z. Wu, and S. Lai, "Miniaturized microstrip array for the UHF-band RFID reader," Microwave and Opt. Techol. Letters, vol. 48, no. 7, pp. 1299-1301, July 2006.

[6] Z. Sun, S. Zhhong, X. Tang, and K. Chen, "Low side-lobe circular polarized microstrip array for $2.45 \mathrm{GHz}$ RFID readers," Microwave and Opt. Tech. Letters, vol. 50, no. 9, pp. 2235-2237, September 2008.

[7] Pavel V. Nikitin and K. V. S. Rao, "Helical antenna for handheld UHF RFID reader," Proc. IEEE International Conference in RFID, Orlando, FL., pp. 169-173, 2010.

[8] B.Y. Feng, "A patch antenna for RFID reader," in Proc. International Conference on Microwave and Millimeter Wave Technology, (ICMMT 2008), vol. 3, pp. 1044-1046, 2008.

[9] S. Kaki, and T. Chakravarty, "Compact printed Yagi antenna for handheld UHF-RFID reader," in Proc. Int. Conference on Devices and Communications (ICDeCom) Symp., pp. 1-3, 2011.

[10] K. M. Luk, and K. W. Leung, Dielectric resonator antenna, Hertfordshire, Research Studies Press, U.K, 2003.

[11] R. Chair, A.A. Kishk, and K.F. Lee, "Comparative study on the mutual coupling between different sized cylindrical dielectric resonator antennas and circular microstrip patch antennas ," IEEE Trans. Antennas Propag., vol. 53, no. 3, pp. 1011-1018, March 2005.

[12] A. Petosa, Dielectric resonator antenna handbook, Artech House Inc., Norwood, 2007.

[13] S. H. Zainud-Deen, Hend A. Malhat, and K. H. Awadalla, "Circular polarized dielectric resonator antenna for portable RFID reader using a single feed," International Journal of Radio Frequency Identification \& Wireless Sensor Networks, vol. 1, no.1, 2011.

[14] S. H. Zainud-Deen, Hend A. Malhat, and K. H. Awadalla, "Dielectric resonator antenna mounted on a circular cylindrical ground plane," Progress In Electromagnetics Research B, PIER B, vol. 19, pp. 427444, 2010.

[15] S. H. Zainud-Deen, Noha A. El-Shalaby, and K. H. Awadalla," Radiation characteristics of cylindrical dielectric resonator antenna mounted on superquadric cylindrical Body," Electrical and Electronic 
Engineering Journal, SAP, vol. 2, No. 3, pp.88-95, 2012.

[16] 27 $7^{\text {th }}$ Applied Computational Electromagnetics Society (ACES) Conference, Williamsburg, Virginia, USA, March 2011.

[17] S. H. Zainud-Deen, Noha A. El-Shalaby, and K. H. Awadalla," Hemispherical DRA antennas mounted on or embedded in circular cylindrical surface for producing omnidirectional radiation pattern". International Journal of Communication, Network and System Sciences, vol.4, no.9, pp. 601-608, September 2011.

[18] D. V. Hutton, Fundamentals of finite element analysis, McGraw- Hills Companies, USA, 2004.

[19] S.J. Cooke, R. Shtokhamer, A.A. Mondelli, and B. Levush," A finite integration method for conformal, structured-grid, electromagnetic simulation," Journal of Computational Physics, vol. 215, pp. 321-347, 2006.

[20] A. A. Kishk, "Performance of planar four element array of single-fed circularly polarized dielectric resonator antenna," Microwave and Optical Technology Lett., vol. 38, no. 5, pp. 381-384, Sep. 2003.

[21] CST MICROWAVE STUDIO®, help, http://www.cst.com.

[22] S. H. Zainud-Deen, Hend A. Malhat, and K. H. Awadalla, "Circular polarized dielectric resonator antenna for portable RFID reader using a single feed," International Journal of Radio Frequency Identification $\mathcal{E}$ Wireless Sensor Networks, vol. 1, no.1, 2011.

[23] M. Haneishi, and h. Takazawa, "Broadband circularly polarized planar array composed of a pair of dielectric resonator antennas," Electronic Lett., vol. 21, no. 10, pp. 437-438, May 1985. 